\title{
Vascular Analysis of Radial Artery Perforator Flaps
}

\author{
Ehtaih Sham, Jaumie Ayala Masia, Thyagraj Jayaram Reddy' \\ Department of Plastic, Craniofacial \& Reconstructive Surgery, Hospital Sant Pau, University Autonoma De Barcelona, Spain, ${ }^{1}$ Department of Plastic, Maxillofacial \& \\ Reconstructive Surgery, Vydehi Institute of Medical Sciences, Bangalore, Karnataka, India
}

\section{Abstract}

Background: Radial forearm free flap with all its present day modifications is the workhorse of soft tissue reconstruction in head \& neck. Although there are several advantages, it requires the sacrifice of a major artery of forearm. There are several modifications of harvesting a forearm flap based on perforator principles. A clear understanding of vascular anatomy of individual perforators relative to its vascular territory $\&$ flow characteristics is essential for both flap harvest \& design. The purpose of this cadaveric observational anatomical study was to determine the location, size \& vascular territory of the radial artery cutaneous perforators. Materials and Methods: 12 fresh human cadavers \& 24 cadaveric forearms were dissected to determine the total number, location, size \& vascular territory of radial artery adipo-fascio cutaneous perforator. The cutaneous territory of distally dominant perforators was analyzed using methylene blue injections \& three-dimensional computed tomographic angiogram. Results: In the 12 fresh human cadavers \& 24 forearm specimens, a total of 222 perforators were dissected for an average of 18.5 radial artery perforators per forearm. Of the total 222 perforators dissected 118 were smaller than $0.5 \mathrm{~mm}$ in diameter ( $53.15 \%$ ) these were not clinically significant. 104 perforators were greater than $0.5 \mathrm{~mm}$ in diameter $(46.84 \%)$ these were clinically significant. Of the 222 radial artery perforators dissected, 127 perforators $(57.20 \%)$ were radially distributed \& 95 perforators $(42.79 \%)$ had ulnar distribution. A total of 90 perforators $(40.54 \%)$ were identified on distal side (Radial styloid) \& 132 perforators $(59.45 \%)$ were identified on proximal side (Lateral epicondyle). Mean number of perforators on radial side was $10.6 \& 7.9$ on ulnar side, a comparison of both using student t paired test gives a $P$ value of 0.006 , which was statistically significant. Comparison of mean number of perforators on the distal side was $7.5 \&$ proximal side was 11.0, Student Paired t test gives a $P$ value of 0.003 , which was statistically significant. Comparison of mean Diameter of perforators between the Distal side (1.11) \& Proximal side (0.86) using Student Paired t test gives a $P$ value of 0.01 which was statistically significant. A chi square test was done to compare mean diameter of perforators on distal side, which were more than $1 \mathrm{~mm}(80 \%) \& 1$ ess than $1 \mathrm{~mm}(20 \%)$ $\&$ on proximal side more than $1 \mathrm{~mm}(35.6 \%) \&$ less than $1 \mathrm{~mm}(64.4 \%)$. Chi square value of 42.406 was obtained, degree of freedom value was $1 \& P$ value of $<0.001$ was achieved which was found to be highly significant. Methylene blue injections into the proximal part of radial artery demonstrated clusters both in proximal \& distal forearm \& also cutaneous territory of flap. Three- dimensional computed tomographic angiography reveals a network of linking vessels found to communicate between adjacent perforators \& running parallel to radial artery. Large network of linking vessels could be found between fascia \& dermis, which also explains the ability to harvest forearm flap at the supra-fascial level. Conclusion: Increase in knowledge of vascular territory of radial artery perforators with regards to numbers, size, location, and cutaneous territory can lead to expanded use of radial forearm flap based on either distal or proximal perforator alone, without sacrificing the radial artery.

Keywords: Anatomy, angio computed tomographic, perforator flap, radial artery, reconstruction, vascularization

\section{INTRODUCTION}

Increased knowledge of vascular anatomy has inevitably led to innovations in flap design and its use in clinical arena. The evolution of random pattern flaps to fasciocutaneous flaps to myocutaneous flaps and finally to the perforator flaps has followed a linear progression, largely because of pioneering vascular anatomical studies. The information derived from such kind of work has fuelled an evolution in flap designs and its clinical applications.

\begin{tabular}{|c|c|}
\hline \multicolumn{2}{|c|}{ Access this article online } \\
\hline Quick Response Code: & $\begin{array}{l}\text { Website: } \\
\text { www.amsjournal.com }\end{array}$ \\
\hline 7 & $\begin{array}{l}\text { DOI: } \\
\text { 10.4103/ams.ams_1_18 }\end{array}$ \\
\hline
\end{tabular}

Since the original description of radial forearm flap in 1978 by Yang and Yuzhi ${ }^{[1]}$ and Timmons anatomical description in 1986, this versatile flap has found numerous applications in plastic and reconstructive surgery. ${ }^{[2]}$ Its value in head-and-neck

Address for correspondence: Dr. Ehtaih Sham, Hospital Sant Pau, University Autonoma De Barcelona, Barcelona, Spain. E-mail: ehtaihsham@yahoo.com

This is an open access journal, and articles are distributed under the terms of the Creative Commons Attribution-NonCommercial-ShareAlike 4.0 License, which allows others to remix, tweak, and build upon the work non-commercially, as long as appropriate credit is given and the new creations are licensed under the identical terms.

For reprints contact: reprints@medknow.com

How to cite this article: Sham E, Masia JA, Reddy TJ. Vascular analysis of radial artery perforator flaps. Ann Maxillofac Surg 2018;8:66-72. 
Sham, et al.: Vascular analysis of radial artery perforators
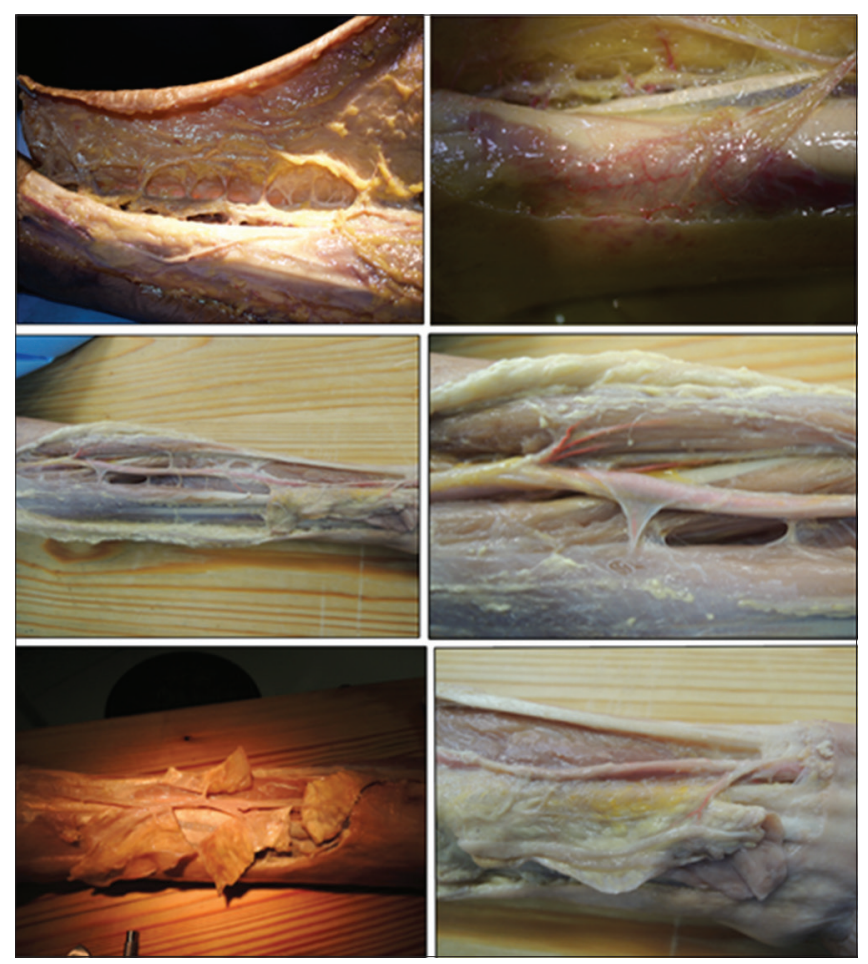

Figure 1: Radial artery perforators to skin
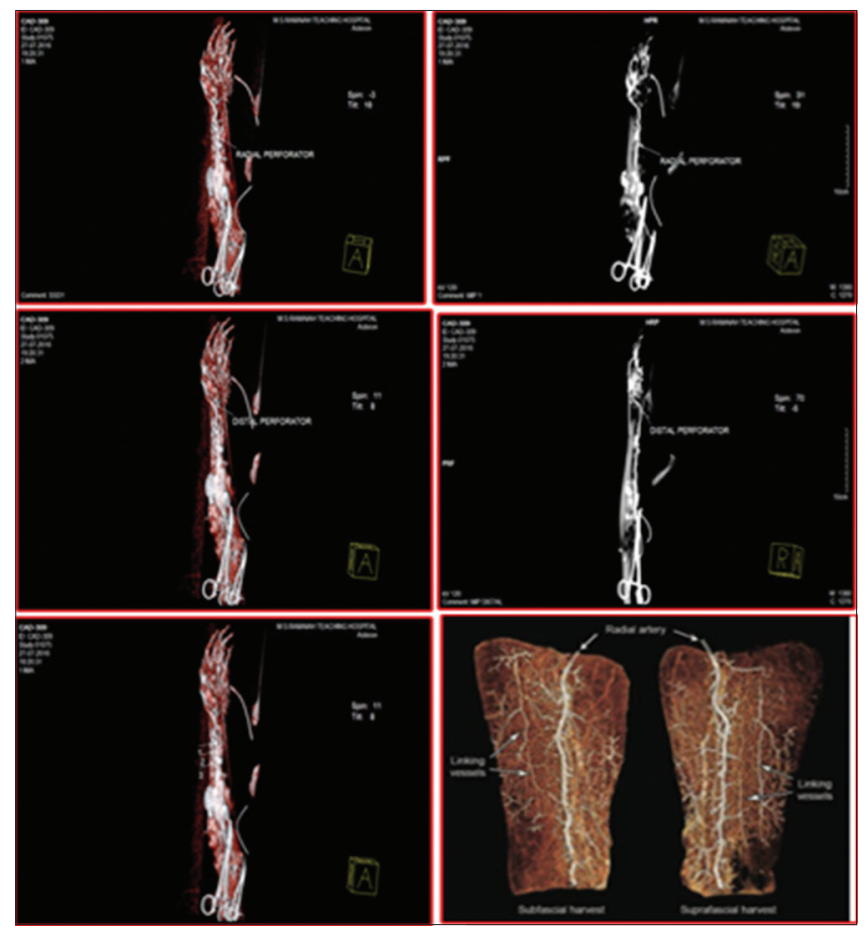

Figure 3: Angiography of radial artery perforators

reconstruction and upperand lowerextremity reconstruction is well documented. Nevertheless, its application as both retrograde flow-pedicled island flap and free flap has resulted in two major drawbacks:

1. Donor site morbidity

2. Sacrifice of the radial artery.

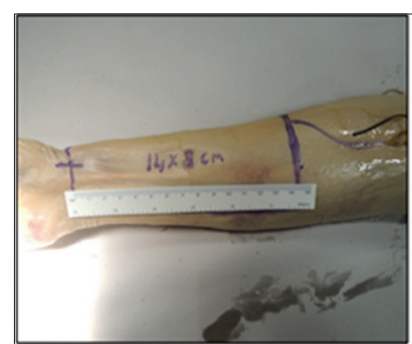

CUTANEOUS TERITORYOF PERFORATOR FLAPDIMENSION
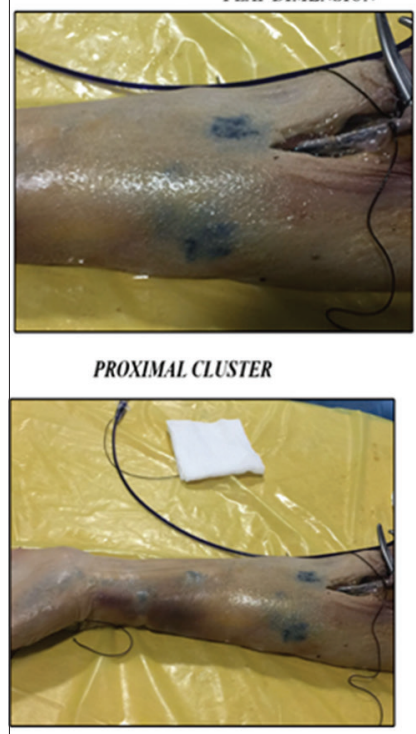

DISTAL.AND PROXIMAL PERFORATOR

Figure 2: Distal and proximal perforators

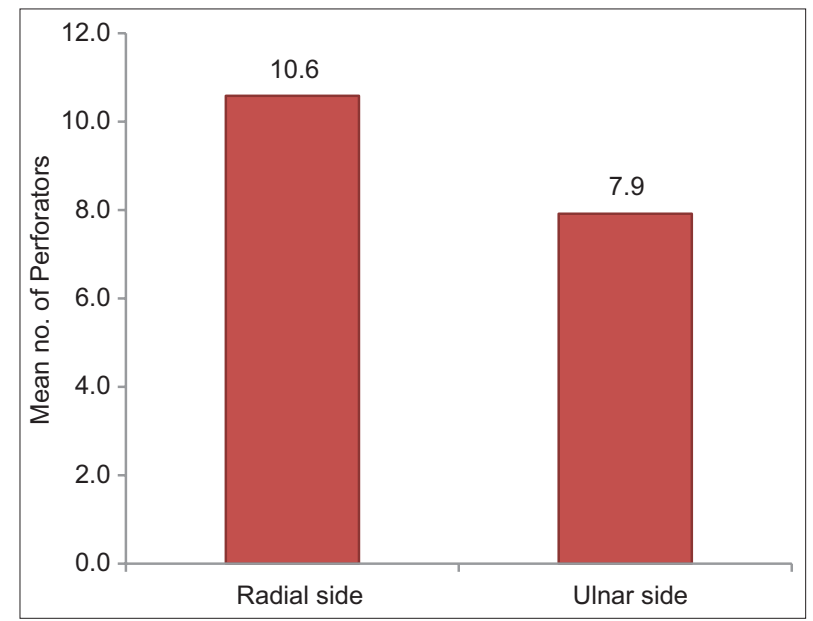

Bar Chart 1: Comparison of mean number of perforators between radial and ulnar side

A study detailing the location and vascular territory of the radial artery perforators, therefore, becomes necessary to facilitate operative planning in perforator-based flap harvest. A well-described territorial outline of the consistently located, clinically significant perforators forms the basis for this observational anatomical study. 
Sham, et al: Vascular analysis of radial artery perforators

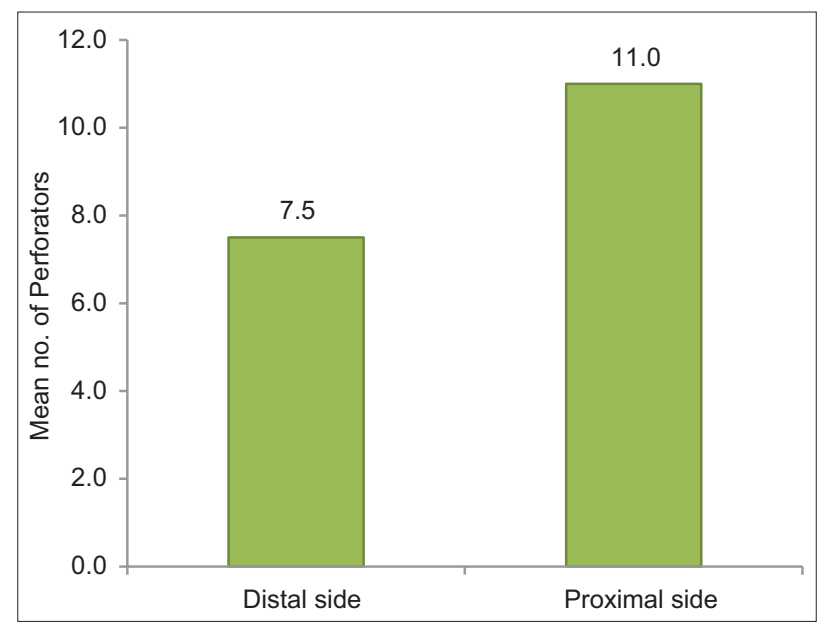

Bar Chart 2: Comparison of mean number of perforators between the distal and proximal side

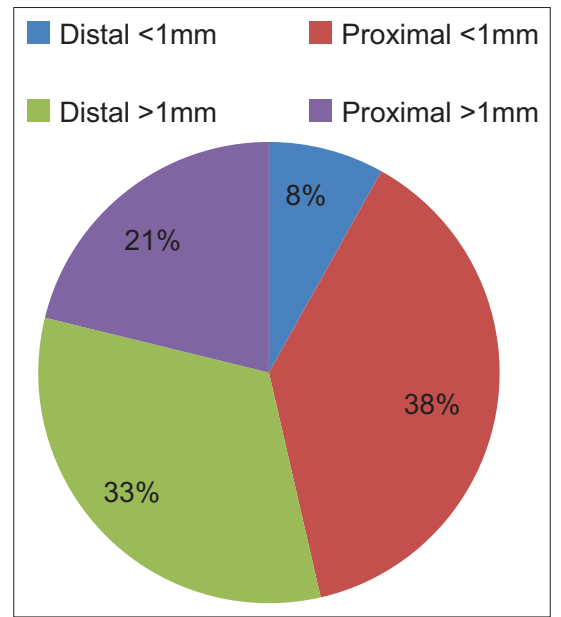

Bar Chart 4: Pictorial presentation of Chi-square test

\section{Materials and Methods}

\section{Objectives}

\section{Observational anatomical study}

To determine the location, size, and vascular territory of the radial artery adipo-fasciocutaneous perforators involving 12 fresh human cadavers and 24 cadaveric forearms.

Need for the study: Anatomical studies defining the perforator vessel anatomy and distribution have been done before. However, there are very few studies defining the location of perforator clusters or the cutaneous territory along the radial artery axis. A well-defined territorial outline of the consistently located, clinically significant perforators would be useful for operative decision-making of shape-modified adipo-fasciocutaneous radial artery perforator flap.

\section{Inclusion criteria}

Twelve fresh human cadavers with normal radial artery anatomy were included in study.

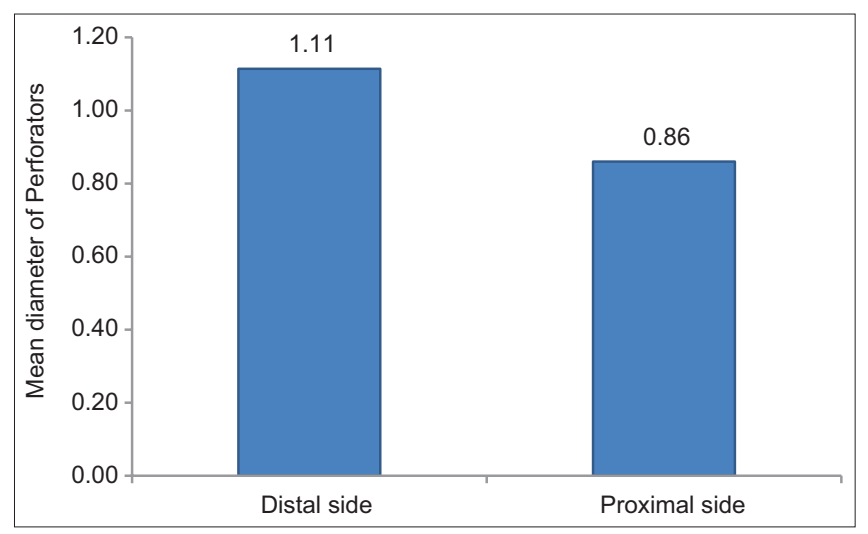

Bar Chart 3: Comparison of mean diameters of perforators between the distal and proximal side

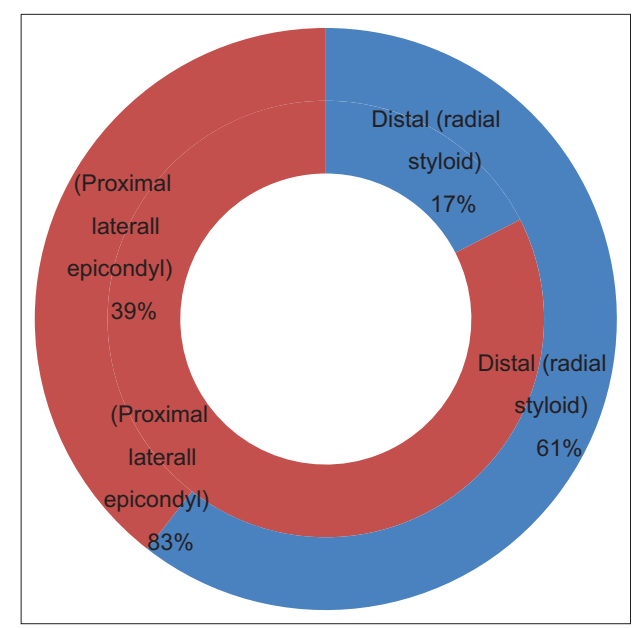

Bar Chart 5: Component chart

\section{Exclusion criteria}

1. Cadavers $>1$-month-old

2. Anomalies of radial artery.

\section{Methodology}

\section{Anatomical study}

Twelve fresh human cadavers and 24 cadaveric forearms were dissected. All radial artery adipo-fasciocutaneous perforators were analyzed for:

1. Number of perforators

2. Orientation of perforators
a. Radial distribution

b. Ulnar distribution.

3. Size of perforators

4. Cutaneous territory.

The upper extremity at the level of the elbow and the brachial artery was cannulated and perfused with warm saline. This was continued until the backflow was clear. Subsequently, the artery was injected with $20 \mathrm{cc}$ of Microfil red and the arm was stored in refrigerator at $0^{\circ} \mathrm{C}$ for $24 \mathrm{~h}$. A total of 24 flaps were dissected to access the size, numbers, and location of the radial artery perforators. Two flaps were 
used for vascular injection studies using methylene blue and lead oxide.

An incision is made on the palmar aspect of the forearm, extending from wrist crease to elbow. All perforators originating from the radial artery are identified and dissected. Parameters include orientation of perforators, whether they arise on the radial side/lateral or on the ulnar side/medial, distance from radial styloid for distal perforators and from the lateral epicondyle for the proximal perforators, external diameter (artery) using digital vernier caliper with an accuracy of $\pm 0.03 \mathrm{~mm}$, and cutaneous cluster pattern with methylene blue injections.

To determine the vascular cutaneous territory of a distally based radial artery perforator flap, two forearm flaps were dissected based on distal most dominant perforator found proximal to the radial styloid. The artery was cannulated and injected with methylene blue dye to examine the territory of cutaneous staining. Contrast material (lead oxide) was then injected and the specimen was subjected to three-dimensional CT scan with volume rendering function in order to access the vascular territory and identify linking vessels communicating with adjacent perforators.

The results were statistically analyzed with Student $t$-paired test and Chi-square test (Software: SPSS 17-Chicago Inc., SPSS version 22, IBM. Corp).

\section{RESULTS}

In the 12 fresh human cadavers and 24 forearm specimens, a total of 222 perforators were dissected for an average of 18.5 radial artery perforators per forearm [Table 1]. Of the total 222 perforators dissected, 118 were smaller than $0.5 \mathrm{~mm}$ in diameter $(53.15 \%)$, these were not clinically significant. A total of 104 perforators were $>0.5 \mathrm{~mm}$ in diameter $(46.84 \%$ ), these were clinically significant [Figure 1].

Of the 222 radial artery perforators dissected, 127 perforators $(57.20 \%)$ were radially distributed and 95 perforators $(42.79 \%)$ had ulnar distribution [Table 1]. A total of 90 perforators $(40.54 \%$ ) were identified on the distal side (radial styloid) and 132 perforators (59.45\%) were identified on the proximal side (lateral epicondyle) [Table 1]. The mean number of perforators on radial side was 10.6 and 7.9 on ulnar side, a comparison of both using Student $t$-paired test gives a $P=0.006$, which was statistically significant [Table 2] [Bar Chart 1]. Comparison of mean number of perforators on the distal side was 7.5 and proximal side was 11.0 , Student paired $t$-test gives a $P=0.003$, which was statistically significant [Table 3] [Bar Chart 2]. Comparison of mean diameter of perforators between the distal side (1.11) and proximal side (0.86), side using Student paired $t$-test gives a $P=0.01$ which was statistically significant [Tables 4-6 and Bar Chart 3].Chi-square test was done to compare the mean diameter of perforators on the distal side, which were $>1 \mathrm{~mm}(80 \%)$ and $<1 \mathrm{~mm}(20 \%)$ and on the proximal side $>1 \mathrm{~mm}(35.6 \%)$ and $<1 \mathrm{~mm}(64.4 \%)$. Chi-square value of 42.406 was obtained, degree of freedom value was 1 and $P<0.001$ was achieved which was found to be highly statistically significant [Table 7] [Bar Charts 4 and 5].

In almost all the dissected anatomical specimens, at least one clinically significant perforator was found within $2 \mathrm{~cm}$ proximal to radial styloid [Figure 2]. Methylene blue injections into the proximal part of radial artery demonstrated clusters

\begin{tabular}{|c|c|c|c|c|c|}
\hline Cadavers & $\begin{array}{l}\text { Number of } \\
\text { perforators }\end{array}$ & $\begin{array}{l}\text { Radial } \\
\text { side }\end{array}$ & $\begin{array}{l}\text { Ulnar } \\
\text { side }\end{array}$ & $\begin{array}{l}\text { Distal } \\
\text { side }\end{array}$ & $\begin{array}{l}\text { Proximal } \\
\text { side }\end{array}$ \\
\hline 1 & 19 & 10 & 9 & 8 & 11 \\
\hline 2 & 21 & 12 & 9 & 11 & 10 \\
\hline 3 & 20 & 11 & 9 & 7 & 13 \\
\hline 4 & 18 & 11 & 7 & 7 & 11 \\
\hline 5 & 12 & 10 & 2 & 7 & 5 \\
\hline 6 & 18 & 10 & 8 & 7 & 11 \\
\hline 7 & 20 & 13 & 7 & 6 & 14 \\
\hline 8 & 16 & 9 & 7 & 5 & 11 \\
\hline 9 & 19 & 10 & 9 & 10 & 9 \\
\hline 10 & 20 & 11 & 9 & 7 & 13 \\
\hline 11 & 21 & 9 & 12 & 9 & 12 \\
\hline 12 & 18 & 11 & 7 & 6 & 12 \\
\hline Total & 222 & 127 & 95 & 90 & 132 \\
\hline
\end{tabular}

Table 2: Comparison of mean number of perforators between the radial and ulnar side-using Student paired $t$-test

\begin{tabular}{|c|c|c|c|c|c|c|c|c|c|}
\hline \multirow[t]{2}{*}{ Sides } & \multirow[t]{2}{*}{$n$} & \multirow[t]{2}{*}{ Mean } & \multirow[t]{2}{*}{ SD } & \multirow[t]{2}{*}{ SEM } & \multirow[t]{2}{*}{ Mean difference } & \multicolumn{2}{|c|}{$95 \% \mathrm{Cl}$ of the difference } & \multirow[t]{2}{*}{$t$} & \multirow[t]{2}{*}{$P$} \\
\hline & & & & & & Lower & Upper & & \\
\hline Radial side & 12 & 10.6 & 1.2 & 0.3 & 2.7 & 0.9 & 4.4 & 3.370 & $0.006^{*}$ \\
\hline Ulnar side & 12 & 7.9 & 2.4 & 0.7 & & & & & \\
\hline
\end{tabular}

$\mathrm{SD}=$ Standard deviation; $\mathrm{SEM}=$ Standard error of mean; $\mathrm{CI}=$ Confidence interval; $0.01 * P$ value is significant

Table 3: Comparison of mean number of perforators between the distal and proximal side-using Student paired $t$-test

\begin{tabular}{|c|c|c|c|c|c|c|c|c|c|}
\hline \multirow[t]{2}{*}{ Sides } & \multirow[t]{2}{*}{$n$} & \multirow[t]{2}{*}{ Mean } & \multirow[t]{2}{*}{ SD } & \multirow[t]{2}{*}{ SEM } & \multirow[t]{2}{*}{ Mean difference } & \multicolumn{2}{|c|}{$95 \% \mathrm{Cl}$ of the difference } & \multirow[t]{2}{*}{$t$} & \multirow[t]{2}{*}{$P$} \\
\hline & & & & & & Lower & Upper & & \\
\hline Distal side & 12 & 7.5 & 1.7 & 0.5 & -3.5 & -5.6 & -1.4 & -3.718 & $0.003 *$ \\
\hline Proximal side & 12 & 11.0 & 2.3 & 0.7 & & & & & \\
\hline
\end{tabular}

$\mathrm{SD}=$ Standard deviation; $\mathrm{SEM}=$ Standard error of mean; $\mathrm{CI}=$ Confidence interval; $0.01 * P$ value is significant 
both in the proximal and distal forearm and also revealed a large flap cutaneous territory [Figure 2].

Three-dimensional computed tomographic angiography [Figure 3] reveals a network of linking vessels found to communicate between adjacent perforators and running parallel to the radial artery. Large network of linking vessels could be found between fascia and dermis, which also explains the ability to harvest forearm flap at the suprafascial level.

\section{Discussion}

Head-and-neck oncologists often seem to confront the difficult task of balancing cancer cure with preservation of function, cosmesis, and quality of life when deciding patients best treatment protocols. Reconstruction in its true sense represents a big challenge for the reconstructive surgeon. ${ }^{[3,4]}$

Since the original description of radial forearm flap in 1978 by Yang and Yuzhi, this versatile flap has found itself numerous applications in plastic and reconstructive surgery. ${ }^{[1,5]}$ However, its application as both retrograde flow pedicled island flap and free flap has resulted in two major drawbacks, drawing great attention among the reconstructive Surgeons: ${ }^{[2,6,7]}$

1. Donor-site morbidity in terms of esthetics, cold intolerance, slight-to-moderate functional deficit

2. Sacrificing a major artery of the forearm.

Several modifications and innovations in terms of donor-site closure, flap-harvesting techniques, and preservation of radial artery have been proposed and practiced. ${ }^{\left[{ }^{8-12]}\right.}$ Increased knowledge of vascular anatomy has played a definitive role in

\begin{tabular}{|c|c|c|}
\hline & Distal (radial styloid) & Proximal (lateral epicondyle) \\
\hline 1 & 1.23 & 0.54 \\
\hline 2 & 1.01 & 1.00 \\
\hline 3 & 1.23 & 0.64 \\
\hline 4 & 0.92 & 0.63 \\
\hline 5 & 1.20 & 0.83 \\
\hline 6 & 1.17 & 0.92 \\
\hline 7 & 0.98 & 1.20 \\
\hline 8 & 0.87 & 1.00 \\
\hline 9 & 1.11 & 0.94 \\
\hline 10 & 1.20 & 0.68 \\
\hline 11 & 1.23 & 0.83 \\
\hline 12 & 1.22 & 1.11 \\
\hline
\end{tabular}

increasing our ability to understand and use perforator-based flaps for various clinical Applications. ${ }^{[13,14]}$

As we gradually shift toward perforator-based flap reconstructions, knowledge of individual perforators should supersede that of source artery. ${ }^{[15]}$ Many surgeons have reported the use of perforator flaps from the forearm with ease, success, and good functional outcome. ${ }^{[16-18]}$ However, it is difficult to clinically establish the exact location of dominant radial artery perforator with a handheld Doppler because of superficial course of the radial artery. ${ }^{[19]}$ To establish the basis for perforator flaps, an anatomical study to determine the exact location and vascular territory become all the more essential. In our present study, we have investigated the location, size and vascular pattern, and territory of the radial artery in 12 fresh human cadavers involving 24 forearm specimens. We have demonstrated a total of 222 perforators with an average of 18.5 perforators per forearm. Perforators $<0.5 \mathrm{~mm}$ were not considered as clinically suitable for anastomosis. Our study confirms a strong relation between the number and diameter of perforators. ${ }^{[19-21]}$ Distal side demonstrates less number of perforators but a large caliber perforator is consistently present within $2 \mathrm{~cm}$ of radial styloid in all of the 12 cadavers, this finding is found to be consistent with the previous anatomical studies on the radial artery. ${ }^{[16]}$ Michel Saint-Cyr et al. conducted an anatomical study in 26 fresh human cadaveric forearms to study and determine the location, orientation, external diameter, and vascular territory of radial artery cutaneous perforators. The authors concluded that there are two main clusters of clinically significant perforators and increased knowledge of size, location, and cutaneous territory of the radial artery perforators can lead to expanded use of radial artery forearm flap based on these cutaneous perforators alone, without sacrificing the main radial artery. ${ }^{[19]}$

In both distal and proximal forearms, perforators arising from the main vessel have both radial and ulnar distribution. ${ }^{[19]}$ These anatomical characteristics suggest an element of safety when harvesting flaps based on either distal or proximal perforator. ${ }^{[19]}$ Our study demonstrates clusters of perforators in both proximal and distal aspect of the forearm. ${ }^{[14,19]}$

Clinical use of perforator-based radial artery free flap may have limited applications, but nevertheless, cases have been reported in the literature. ${ }^{[22]}$ The vascular anatomy of the fascia and subcutaneous tissue of the distally based flaps have been well described. ${ }^{[17]}$ The blood supply to the fasciocutaneous flap is found to originate from 5 to 10 septocutaneous perforators arising from the radial artery in the anatomical snuffbox. ${ }^{[16]}$

Table 5: Comparison of mean diameter of perforators between the distal and proximal side-using Student paired $t$-test

\begin{tabular}{|c|c|c|c|c|c|c|c|c|c|}
\hline \multirow[t]{2}{*}{ Sides } & \multirow[t]{2}{*}{$n$} & \multirow[t]{2}{*}{ Mean } & \multirow[t]{2}{*}{ SD } & \multirow[t]{2}{*}{ SEM } & \multirow[t]{2}{*}{ Mean difference } & \multicolumn{2}{|c|}{$95 \% \mathrm{Cl}$ of the difference } & \multirow[t]{2}{*}{$t$} & \multirow[t]{2}{*}{$P$} \\
\hline & & & & & & Lower & Upper & & \\
\hline Distal & 12 & 1.11 & 0.13 & 0.04 & 0.25 & 0.08 & 0.43 & 3.132 & $0.01 *$ \\
\hline Proximal & 12 & 0.86 & 0.21 & 0.06 & & & & & \\
\hline
\end{tabular}

$\mathrm{SD}=$ Standard deviation; $\mathrm{SEM}=$ Standard error of mean; $\mathrm{CI}=$ Confidence interval; $0.01 * P$ value is significant 
Sham, et al.: Vascular analysis of radial artery perforators

\begin{tabular}{lclc}
\hline \multicolumn{4}{l}{ Table 6: Mean number and diameter on both sides } \\
\hline Sides & Mean & Sides & Mean \\
\hline Radial side & 10.6 & Distal side & 7.5 \\
Ulnar side & 7.9 & Proximal side & 11.0 \\
\hline
\end{tabular}

\begin{tabular}{lccccc}
\hline \multicolumn{2}{l}{ Table 7: Chi-Square test } \\
\hline $\begin{array}{c}\text { Distal (radial } \\
\text { styloid) (\%) }\end{array}$ & $\begin{array}{c}\text { (proximal lateral } \\
\text { epicondyle) (\%) }\end{array}$ & $\chi^{2}$ & df & $\boldsymbol{P}$ \\
\hline$<1 \mathrm{~mm}$ & $18(20)$ & $85(64.4)$ & 42.406 & 1 & $<0.001$ \\
$>1 \mathrm{~mm}$ & $72(80)$ & $47(35.6)$ & & & \\
\hline
\end{tabular}

Anatomical and clinical investigation of the radial forearm adipo-fascial flap based on distal perforators has been well described by Hamdy El-Khatib, who reported an anatomic study in 11 fresh and fixed cadavers, designing an island adipofascial flap based on distal five to eight septocutaneous perforators of the radial artery and their vena comitantes, great advantage being preservation of the radial artery. ${ }^{[14]}$ Three-dimensional computed tomographic angiography in our study has shown a comparable vascular territory with linking vessels found to communicate between adjacent perforators and running parallel to the radial artery. ${ }^{[19]}$ Perforators travel to dermis and form a network of linking vessels found between fascia and dermis. This finding is consistent as reported by previous similar studies ${ }^{[14,16]}$ Mark Schaverien and Saint-Cyr conducted a study involving 12 fresh human cadavers and 24 radial forearm flaps harvested from these cadavers to elucidate the role of deep fascia in perfusion of radial forearm flap. The authors concluded that inclusion of deep fascia during flap harvest does not contribute to flap perfusion or vascularity. ${ }^{[17]}$ Although there are several anatomical study reports on vascular anatomy of the radial artery, our study demonstrates the cutaneous territory and location of clusters in detail. The results obtained from our study are clinically important in planning the exact dimension of the flap based on distal third perforators of the radial artery. Perhaps, the most significant finding in this study is the location of cutaneous perforators. Knowledge of these perforators can greatly facilitate the reconstructive surgeon in safe flap harvest and design. ${ }^{[23]}$ Both distal and proximal perforators can be used in the designing of potential flaps for various reconstructive needs. ${ }^{[16]}$ Three-dimensional computed tomographic angiogram confirms that suprafacial dissection does not compromise blood supply of the radial forearm pedicle perforator flap. ${ }^{[7,10]}$ The supply to the skin is ensured by means of multiple perforators originating from the radial and ulnar sides of the radial artery, traveling to the skin and communicating with each other in the subcutaneous tissue plane by multiple linking vessels. Each perforator has its own vascular territory, called a perforasome. These perforasomes are linked to one another by both direct and indirect linking vessels, which themselves are linked by communicating branches. These numerous branches confer further protection from ischemia and vascular injury and explain the survival of single dominant perforator-based flaps. ${ }^{[19]}$ Linking vessels allow communication with adjacent perforasomes and follow a direction that is parallel to the direction of perforator flow. Therefore, perforator flap skin paddles should be parallel to the linking vessel orientation, which makes it possible to harvest large flaps based on single dominant perforator. ${ }^{[12,19]}$

\section{Conclusion}

Each perforator holds a unique vascular territory. Vascular supply chain among perforators is highly complex and both direct and indirect linking vessels play a major role in maintaining flap perfusion. Our study demonstrates a consistent course of the radial artery with clusters originating on both distal and proximal ends, with each end becoming a pivot point for a pedicled flap rotation. Each perforator has the potential to become either a free or a pedicled flap depending on the size. In addition, preservation of the radial artery and ability of suprafacial harvest further lessens the morbidity burden. This phenomenon allows a myriad of perforator flap designs that can be tailored to match reconstructive defects. Present day reconstructive surgeons have more options and alternatives in replacing like with like. Local flap alternatives become more plentiful and flap design is limited only by the availability of clinically relevant perforators close to the defect. Freestyle perforator flaps are present day reality, based on the size and length of their respective source arteries and veins.

\section{Financial support and sponsorship}

Nil.

\section{Conflicts of interest}

There are no conflicts of interest.

\section{RefEREnCES}

1. Yang G, Chen B, Gao Y, Liu X, Li J, Jiang S. Forearm free skin flap transplantation. Nat 1 Med J China 1981;61:139-41.

2. Timmons MJ, Missotten FE, Poole MD, Davies DM. Complications of radial forearm flap donor sites. Br J Plast Surg 1986;39:176-8.

3. Mühlbauer W, Herndl E, Stock W. The forearm flap. Plast Reconstr Surg 1982;70:336-44.

4. Soutar DS, McGregor IA. The radial forearm flap in intraoral reconstruction: The experience of 60 consecutive cases. Plast Reconstr Surg 1986;78:1-8.

5. Song R, Gao Y, Song Y, Yu Y, Song Y. The forearm flap. Clin Plast Surg 1982;9:21-6.

6. Lovie MJ, Duncan GM, Glasson DW. The ulnar artery forearm flap. Br J Plast Surg 1984;37:486-92.

7. Chang SC, Miller G, Halbert CF, Yang KH, Chao WC, Wei FC, et al. Limiting donor site morbidity by suprafascial dissection of the radial forearm flap. Microsurgery 1996;17:136-40.

8. Partecke BD, Buck-Gramcko D, Pachucki A. Use of a fascia flap of the forearm in soft tissue defects of the extremities. Handchir Mikrochir Plast Chir 1986;18:353-5.

9. Liang MD, Swartz WM, Jones NF. Local full-thickness skin-graft coverage for the radial forearm flap donor site. Plast Reconstr Surg 1994;93:621-5.

10. Webster HR, Robinson DW. The radial forearm flap without fascia and other refinements. Eur J Plast Surg 1995;18:11-3.

11. Wolf KD, Ervens J, Hoffmeister B. Improvement of radial forearm donor site by prefabrication of facial split thickness skin grafts. Plast Reconstr Surg 1995;98:358-61. 
12. Hussein Mahmoud W. Radial forearm flap versus radial adipofascial perforator based flap for reconstruction of hand soft tissue defects. Donnish J Med Med Sci 2015;2:19-25.

13. Rath T, Millesi W, Millesi-Schobel G, Lang S, Glaser C, Todoroff B, et al. Mucosal prelaminated flaps for physiological reconstruction of intraoral defects after tumour resection. Br J Plast Surg 1997;50:303-7.

14. el-Khatib H, Zeidan M. Island adipofascial flap based on distal perforators of the radial artery: An anatomic and clinical investigation. Plast Reconstr Surg 1997;100:1762-6.

15. Yang D, Morris SF, Tang M, Geddes CR. Reversed forearm island flap supplied by the septocutaneous perforator of the radial artery: Anatomical basis and clinical applications. Plast Reconstr Surg 2003;112:1012-6.

16. Tiengo C, Macchi V, Porzionato A, Bassetto F, Mazzoleni F, De Caro R, et al. Anatomical study of perforator arteries in the distally based radial forearm fasciosubcutaneous flap. Clin Anat 2004;17:636-42.

17. Schaverien M, Saint-Cyr M. Suprafascial compared with subfascial harvest of the radial forearm flap: An anatomic study. J Hand Surg Am 2008;33:97-101.

18. Mateev MA, Ogawa R, Trunov L, Moldobaeva N, Hyakusoku H.
Shape-modified radial artery perforator flap method: Analysis of 112 cases. Plast Reconstr Surg 2009;123:1533-43.

19. Saint-Cyr M, Mujadzic M, Wong C, Hatef D, Lajoie AS, Rohrich RJ, et al. The radial artery pedicle perforator flap: Vascular analysis and clinical implications. Plast Reconstr Surg 2010;125:1469-78.

20. Lin JY, Cheng MH, Wei FC, Song D, Huang WC. Proximal forearm flap based on a septocutaneous vessel from the radial artery. Plast Reconstr Surg 2006;117:955-60.

21. Tiengo C, Macchi V, Porzionato A, Stecco C, Parenti A, Bassetto F, et al. The proximal radial artery perforator flap (PRAP-flap): An anatomical study for its use in elbow reconstruction. Surg Radiol Anat 2007;29:245-51.

22. Raphael Ciuman and Phillip Dost. The Forearm Free Flap- Indications, Appropriate Selection, Complications \& Functional Outcomes; 2012. Available from: http://www.intechopen.com. [Last accessed on 2012 May 05].

23. Giordano L, Bondi S, Ferrario F, Fabiano B, Bussi M. Radial forearm free flap surgery: A modified skin-closure technique improving donor-site aesthetic appearance. Acta Otorhinolaryngol Ital 2012;32:158-63. 